\title{
Hospital-Prevalence of Theileria annulata Infection in Cattle-Calves Determined by Blood Smear and Lymph Node Aspirate Smear Examination in Bikaner, Rajasthan, India
}

\author{
Pavan Goyal*, Anju Chahar, R.K. Tanwar, Fakhruddin and B.N. Shringi \\ Department of Epidemiology and Preventive Veterinary Medicine, College of Veterinary and \\ Animal Science, Rajasthan University of Veterinary and Animal Sciences, \\ Bikaner-334001, Rajasthan, India \\ *Corresponding author
}

\section{A B S T R A C T}

\begin{tabular}{|l|}
\hline K e y w o r d s \\
$\begin{array}{l}\text { Cattle-calves, Piroplasms, } \\
\text { schizonts, Theileria } \\
\text { annulata, Lymph node }\end{array}$ \\
\hline Article Info \\
\hline $\begin{array}{l}\text { Accepted: } \\
\text { 06 May 2018 } \\
\text { Available Online: } \\
\text { 10 June 2018 }\end{array}$ \\
\hline
\end{tabular}

One hundred cattle-calves irrespective of their age, sex and breed brought to Teaching Veterinary Clinical Complex, College of Veterinary and Animal Science, Bikaner were screened for Theileria annulata infection. Blood and lymph node aspirate smears were prepared from the ear vein and enlarged superficial lymph nodes of suspected cattle-calves and stained with Giemsa's stain for detection of piroplams and schizonts under oil immersion, respectively. Blood smear examination revealed presence of piroplasms in seven cases. There was anisocytosis and poikilocytosis observed in erythrocytes structure and infected erythrocytes were appeared as echinocytes. Lymph node aspirate smears examination revealed presence of schizonts in lymphocytes only in three cases and presence of releasing merozoites from the infected cell only in one out of three cases. Thus, the hospital prevalence of Theileria annulata infection in cattle-calves in Bikaner was $7 \%$ and $3 \%$ by Giemsa stained blood smear and lymph node aspirate smear examination, respectively.

\section{Introduction}

Bovine tropical theileriosis is a protozoan disease caused by blood protozoa Theileria annulata and it is transmitted by tick Hyalomma anatolicum anatolicum. It causes significant economic losses in large parts of Asia (Hasanpour et al., 2013). It is mainly seen in cattle, sheep and goat as well as in wild and captive ungulates (Radostits et al., 2007). This intracellular infection inflicts economic burden on cattle breeders in terms of mortality and morbidity as well as expenses spent on prophylactic measures against disease and treatment (Durrani et al., 2008).

Theileria spp. infection can cause acute, subacute or chronic disease pathology (Gill et al., 1977). In T. annulata infection, the most common clinical symptoms are weakness, weight loss, anorexia, high body temperature, petechia on the conjunctival mucosa, swollen lymph nodes, anaemia and cough. On later stages of theileriosis, infected animals cannot stand up, their body temperatures are under normal values $\left(<38.5^{\circ} \mathrm{C}\right)$, and icterus, 
dehydration and blood in faeces are the occasional clinical symptoms (Bakheit et al., 2004). Calves ( $\leq 4$ months of age) infected with Theileria annulata suffered from emaciation, anaemia, unilateral or bilateral exophthalmia, petechiae in conjunctiva, oral and nasal mucosa, and occasionally in the pinnae. Widespread subcutaneous nodules with 0.5 to $3.0 \mathrm{~cm}$ diameter are also detected, as well as enlarged superficial lymph nodes, particularly the submandibular, the retropharyngeal and sometimes the prescapular (Branco et al., 2010).

Tanwar et al., (1984) reported 48.85 per cent prevalence of theileriosis in Rathi calves during 1979-1980 from Bikaner region by Giemsa stained blood smear examination. Martin-Sanchez et al., (1999) analyzed 214 samples out of which, 78.04 per cent, 69.86 per cent, and 62.26 per cent were found to be positive by nested PCR, indirect immunofluorescent antibody test, and optical microscopy of Giemsa-stained smears, respectively. Omer et al., (2002) examined 403 adult and young Holstein Friesian cattle clinically and parasitologically out of which, 62 (15.4 per cent) were found positive for $T$. annulata microscopically. An average of 1-5 piroplasmic forms in the $\mathrm{RBC}$ were observed in all cases with a range of 10-45 per cent parasitemia. Sayin et al., (2003) conducted blood smear and serological examination of the 198 cattle in March, before the start of the first disease season. The prevalence of piroplasmosis was 11.1 per cent (22 out of 198) and the seroprevalence of $T$. annulata was 10.6 per cent (21 out of 198). Dumanli et al., (2005) reported 19.7 per cent (293/1483) prevalence of Theileria annulata by microscopic examination. Aktas et al., (2006) examined 252 blood samples out of which, 41(16.26 per cent) were positive for piroplasms upon microscopic examination. Ananda et al., (2009) screened a total of 132 clinically suspected blood samples from cross- bred cattle by Giemsa's stain out of which, 57 (43.18 per cent) animals were found positive for haemoprotozoan parasites. Out of 57 positive cases, 41 (31.06 per cent) were found positive for Theileria annulata alone. Durrani et al., (2010) collected blood samples from three districts of Punjab province (Pakistan) to examine presence of haemoprotozoans in cattle and reported 6.8 per cent prevalence of Theileria parasite by microscopy. Shahnawaz et al., (2011) reported 3 per cent prevalence of Theileria annulata in large ruminants in Southern Punjab (Pakistan). Khattak et al., (2012) collected 95 examined blood samples from two districts of Southern Punjab. Only five (5.2 per cent) of 95 blood samples were found parasite positive during microscopic examination of Giemsa stained blood smears. Prevalence of $T$. annulata was significantly $(\mathrm{P}=0.053)$ higher in Kohat district as compared to Peshawar. Saeid et al., (2013) examined 150 smears microscopically out of which, 16 (10.66 per cent) were positive for piroplasmic forms of Theileria annulata. Ariyaratne et al., (2014) reported 7.31 per cent (3/41) prevalence of Theileria infection by light microscopic examination of thin blood smears. Kohli et al., (2014) reported 27.2 per cent prevalence of theileriosis by blood smear examination. Singh et al., (2014) carried out study on evaluation of clinical markers for diagnosis of bovine theileriosis and reported that blood smear examination revealed presence of only schizonts in mononuclear cells of 14.29 per cent (3/21) and presence of only piroplasms in the RBCs of 42.86 per cent (9/21) samples. Modi et al., (2015) screened 117 cows for Theileria annulata infection out of which, 20 (17.09 per cent) were found positive for infection on the basis of cytoplasmic inclusions in Giemsa stained peripheral blood smear examination. Tuli et al., (2015) collected a total of 1278 blood samples from twenty districts falling in five major agro-climatic zones of Punjab. Out of which 118 samples (9.23 per cent) were found 
positive for Theileria spp. by Giemsa stained blood smear (GSTBS) examination

\section{Materials and Methods}

One hundred cattle-calves irrespective of their age, sex and breed brought to Teaching Veterinary Clinical Complex of College of Veterinary and Animal Science, Bikaner for treatment were screened for bovine tropical theileriosis. Blood smears were prepared from ear vein of suspected cattle-calves. Lymph node aspiration fluid was collected from the superficial lymph nodes which were infected and enlarged, adopting all aseptic precautions for detection of Koch's blue bodies (K.B.B.) in the lymph node aspirate smear. The 22 gauze needle (sterilized) was used for this purpose. After grasping the affected lymph node between thumb and index finger, the needle was allowed to penetrate inside the lymph node and then moved forward and backward in the lymph node tissue. A small quantity of the fluid was then aspirated with syringe. Immediately after aspiration of lymph fluid, smears were prepared on clean, greaseless glass slides and air dried. Smears were stained with Giemsa's stain as per procedure described by Soulsby (1982) and examined under oil immersion.

\section{Results and Discussion}

Examination of Giemsa's stained blood smears under oil immersion lens revealed intra-erythrocytic piroplasms of Theileria annulata only in seven out of one hundred cases examined. Mostly, the piroplasms were appeared as ring or oval shaped with a little percentage of dots. There was anisocytosis and poikilocytosis observed in erythrocytes structure and infected erythrocytes were appeared as echinocytes (Fig. 1, 2 and 3). Similar findings have been reported by Khan et al., (2011) and Al-Emarah et al., (2012). Abnormalities in erythrocytes structure including anisocytosis, poikilocytosis, basophilic stippling and presence of reticulocytes were also observed by Durrani and Kamal (2008).

Examination of Giemsa's stained lymph node aspirate smears under oil immersion lens revealed presence of schizonts (Koch's blue bodies) in and outside of lymphocytes only in three out of one hundred cases examined and presence of releasing merozoites from the infected cell only in one case (Fig. 4, 5 and 6).

Thus, the hospital prevalence of Theileria annulata infection in cattle-calves was $7 \%$ and $3 \%$ by blood smear and lymph node aspirate smear examination, respectively in Bikaner, Rajasthan. Prevalence of Theileria annulata infection by microscopic examination has been reported by many researchers namely Martin-Sanchez et al., (1999) as 62.26 per cent; Omer et al., (2002) as 15.4 per cent; Sayin et al., (2003) as 11.1 per cent; Dumanli et al., (2005) as 19.7 per cent; Aktas et al., (2006) as 16.26 per cent; Ananda et al., (2009) as 31.06 per cent; Durrani et al., (2010) as 6.8 per cent; Shahnawaz et al., (2011) as 3 per cent; Khattak et al., (2012) as 5.2 per cent; Saeid et al., (2013) as 10.66 per cent; Ariyaratne et al., (2014) as 7.31 per cent; Kohli et al., (2014) as 27.2 per cent; Singh et al., (2014) as 14.29 per cent schizont form and 42.86 per cent piroplasmic form; Modi et al., (2015) as 17.09 per cent schizont form and Tuli et al., (2015) as 9.23 per cent.

The abnormality in erythrocytes shape is mainly due to toxic action of parasite in the erythrocytes, erythrocyte oxidation, and immune-mediated process as reported by Stockham et al., (2000) and Singh et al., (2001). Conventional diagnosis of tropical theileriosis depends on examination of Giemsa stained thin blood and lymph node aspirate smears. 
Fig.1 Dominant ring shaped intra-erythrocytic piroplasms of Theileria annulata in Giemsa stained blood smear (100X)

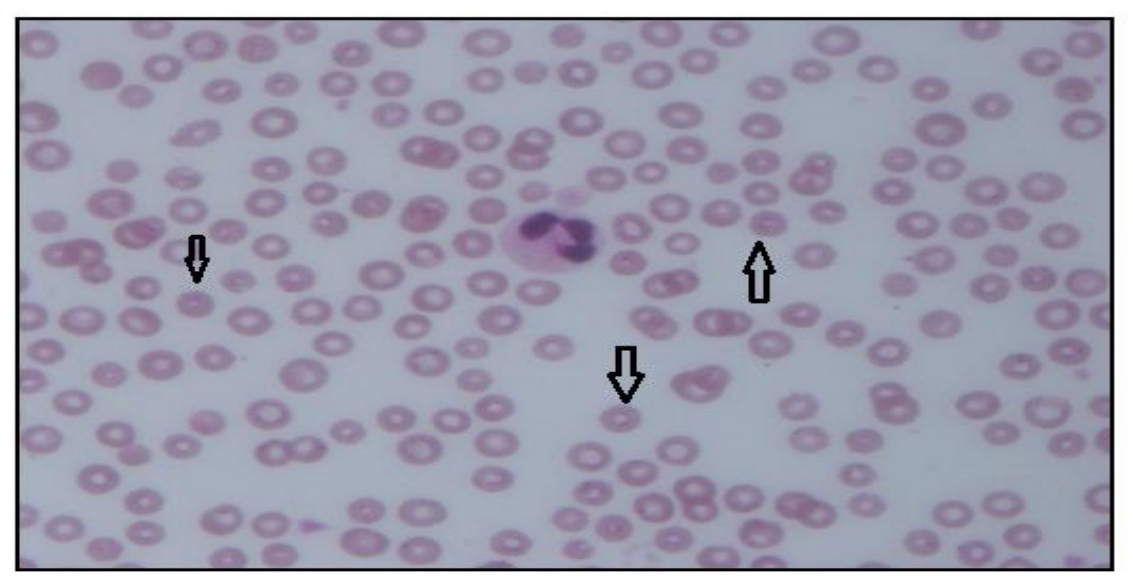

Fig.2 Dot shaped intra-erythrocytic piroplasms of Theileria annulata (Black arrows), anisocytosis and poikilocytosis in erythrocytes structure (White arrows) in Giemsa stained blood smear (100X)

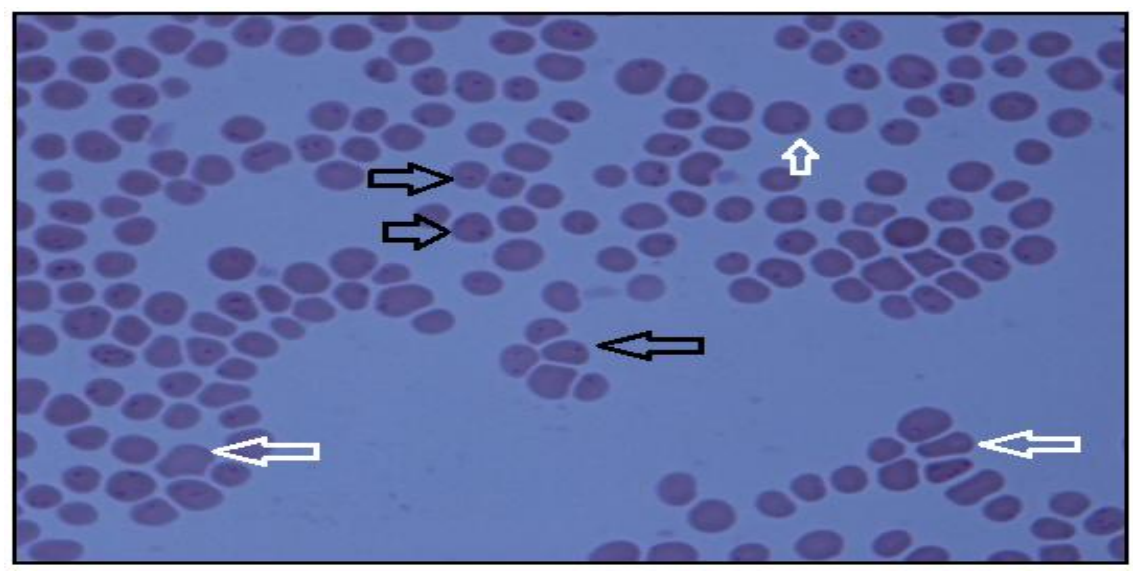

Fig.3 Echinocytes in Giemsa stained blood smear (Under 100X)

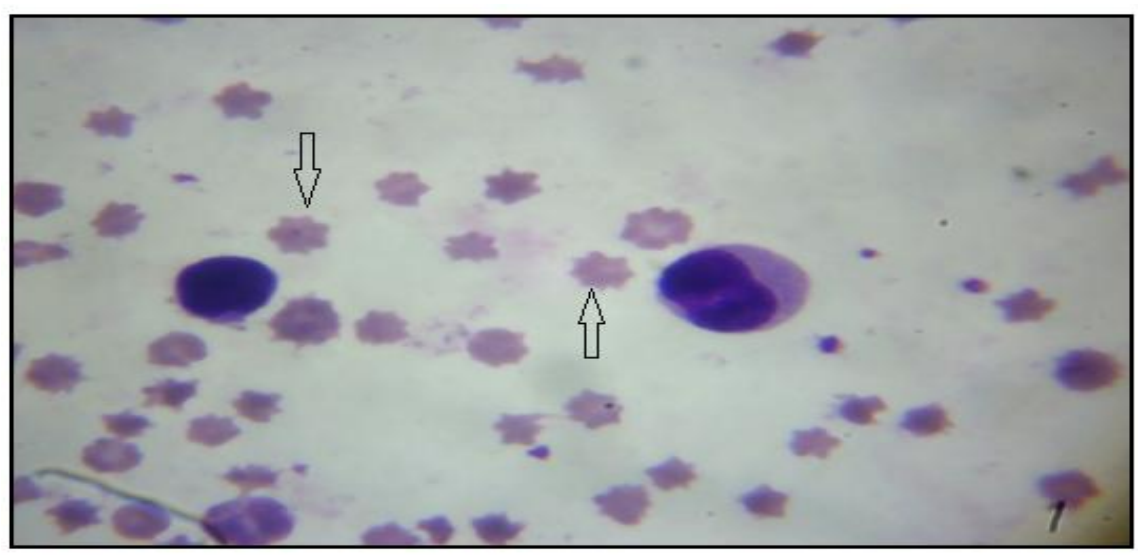


Fig.4 Koch's blue bodies (intracellular schizonts) in infected mononuclear cells in Giemsa stained lymph node aspirate smear (Under 100X)

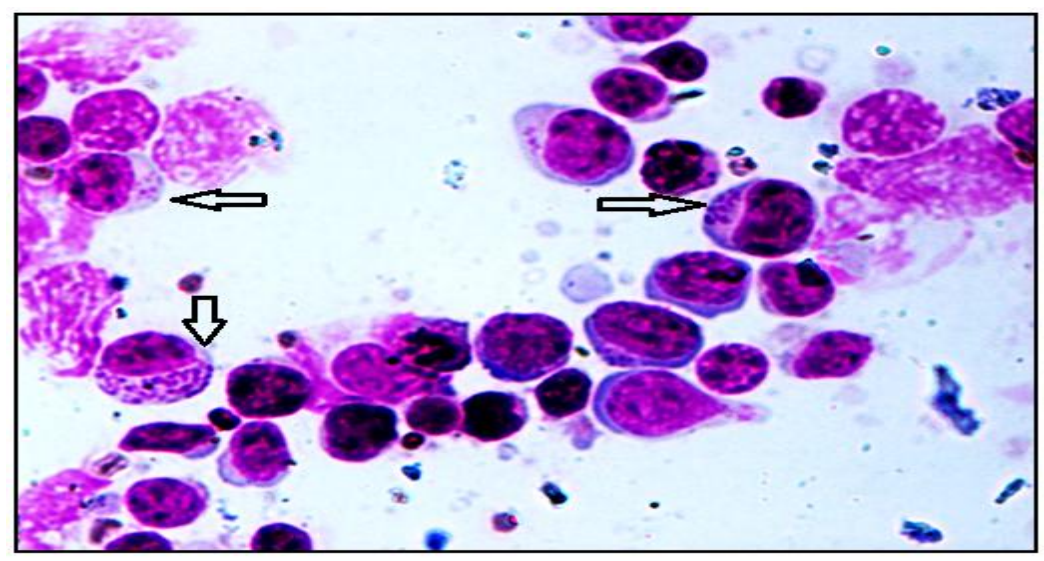

Fig.5 Extracellular schizonts (Koch's blue bodies) outside the lymphocytes (red arrow) and intracellular schizonts in infected lymphocytes (black arrow) in Giemsa stained lymph node aspirate smear (Under 100X)

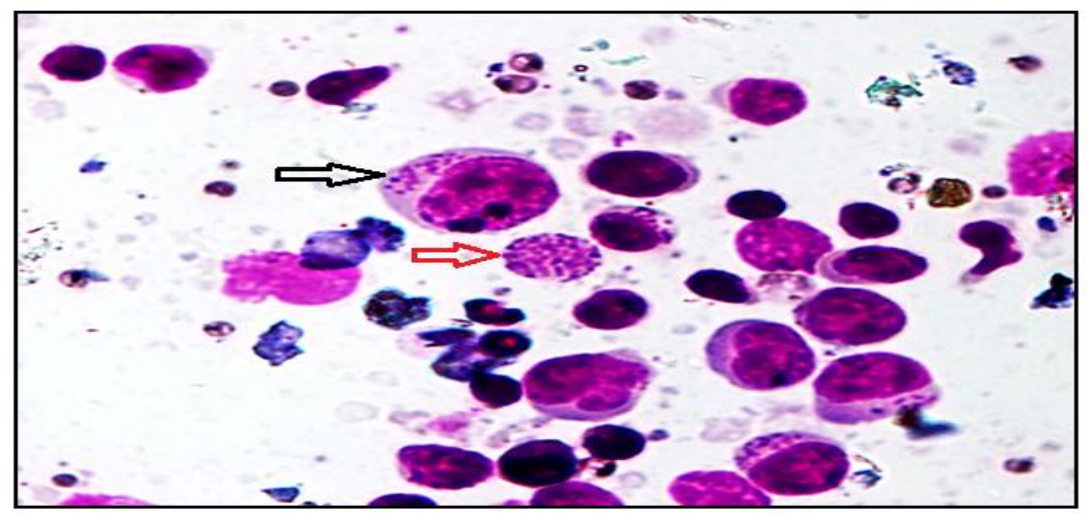

Fig.6 Releasing merozoites from the infected cell in Giemsa stained lymph node aspirate smear examination (Under 100X)

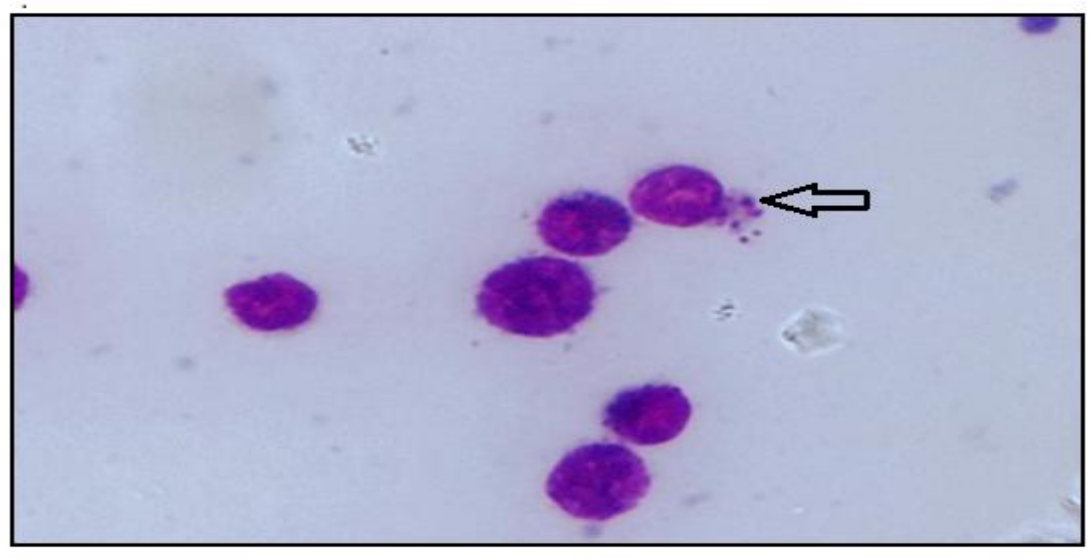


This method is limited to the acute stage of the disease where the parasitemia is high enough to be detected microscopically. During chronic and carrier stages the level of parasitemia usually below the microscopical detectable level.

\section{Acknowledgements}

The authors are highly thankful to the Dr. S.K. Kashyap, Professor and Head, Department of Microbiology and Biotechnology and Dr. G.C. Gahlot, Professor and Head, Department of Animal Genetics and Breeding, College of Veterinary and Animal Science, Bikaner, Rajasthan for providing necessary facilities to carry out the present investigation. This study is financially supported by the Rajasthan University of Veterinary and Animal Sciences, Bikaner, Rajasthan.

\section{Conflict of Interest}

The author declares that he has no conflict of interest.

\section{References}

Aktas, M., Altay, K. and Dumanli, N. 2006. A molecular survey of bovine Theileria parasites among apparently healthy cattle and with a note on the distribution of ticks in eastern Turkey. Veterinary Parasitology. 138: 179-185.

Al-Emarah, G.Y.A., Khudor, M.H. and Daham, H.R. 2012. Clinical, haematological and biochemical study to cattle naturally infected with Theileria annulata in north of Basrah province, AL-Qadisiya. Journal of Vet. Med. Sci. 11(1): 54-62.

Ananda, K.J., D'Souza, P.E. and Puttalakshmamma, G.C. 2009. Prevalence of haemoprotozoan diseases in cross-bred cattle in Bangalore North. Veterinary World. 2(1): 15-16.

Ariyaratne, M.E.S.A. De S., Gothami, W.S. and Rajapakse, R.V.P.J. 2014. Application of PCR technique on confirming Theileria Infection in Cattle and Buffaloes with determining the relationship between Animals' PCV and WBC Count with the Infection. International Journal of Scientific and Research Publications. 4(7): 2250-3153.

Bakheit, M.A., Schnittger, J., Salih, D.A., Boguslawski, K., Beyer, D., Fadl, M. and Ahmed, J.S. 2004. Application of the recombinant Theileria annulata surface protein in an indirect ELISA for the diagnosis of tropical theileriosis. Parasitology Research. 92: 299-302.

Branco, S., Orvalho, J., Leitao, A., Pereira, I., Malta, M., Mariano, I., Carvalho, T., Baptista, R., Shiels, B.R. and Peleteiro, M.C. 2010. Fatal cases of Theileria annulata infection in calves in Portugal associated with neoplastic-like lymphoid cell proliferation. Journal of Veterinary Science. 11(1): 27-34.

Dumanli, N., Aktas, M., Cetinkaya, B., Cakmak, A., Koroglu, E., Saki, C.E., Erdogmus, Z., Nalbantoglu, S., Ongor, H., Simsek, S., Karahan, M. and Altay, K. 2005. Prevalence and distribution of tropical theileriosis in Eastern Turkey. Veterinary Parasitology. 127: 9-15.

Durrani, A.Z. and Kamal, N. 2008. Identification of ticks and detection of blood protozoa in Friesian cattle by polymerase chain reaction test and estimation of blood parameters in district Kasur, Pakistan. Trop. Anim. Health Prod. 40: 441-447.

Durrani, A.Z., Mahmood, N. and Shakoori, A.R. 2010. Comparison of three diagnostic methods for Theileria annulata in Sahiwal and Friesian cattle in Pakistan. Pak. J. Zool. 42(4): 467472. 
Durrani, A.Z., Shakoori, A.R. and Kamal, N. 2008. Bionomics of Hyalomma ticks in three districts of Punjab. Pakistan J. Anim. Plant Sci. 18(1): 20-23.

Gill, B.S., Bhattacharyulu, Y. and Kaur, D. 1977. Symptoms and pathology of experimental bovine tropical theileriosis (Theileria annulata infection). Annales de Parasitologie Humaine et Comparee. 52: 597-608.

Hasanpour, A., Sabegh, Y.G. and Sadeghinasab, A. 2013. Assessment of serum antioxidant enzymes activity in cattle suffering from theileriosis. European Journal of Experimental Biology. 3(1): 493-496.

Khan, I.A., Khan, A., Hussein, A., Riaz, A. and Aziz, A. 2011. Haematobiochemical alterations in cross-bred cattle affected with bovine theileriosis in Semi-Arid Zone. Pak. Vet. Journal. 31(2): 137-140.

Khattak, R.M., Rabib, M., Khan, Z., Ishaq, M., Hameed, H., Taqddus, A., Faryal, M., Durranis, S., Gillani, Q.U.A., Allahyar, R., Shaikh, R.S., Khan, M.A., Ali, M. and Iqbal, F. 2012. A comparison of two different techniques for the detection of blood parasite, Theileria annulata, in cattle from two districts in Khyber Pukhtoon Khwa province (Pakistan). http://www. parasite-journal.org or http://dx.doi. org/10.1051/ parasite/2012 191091: 9195.

Kohli, S., Atheya, U.K. and Thapliyal, A. 2014. Prevalence of theileriosis in cross-bred cattle: its detection through blood smear examination and polymerase chain reaction in Dehradun district, Uttarakhand, India. Veterinary World. 7(3): 168-171.

Martin-Sanchez, J., Viseras, J., Adroher, F.J. and Garcia-Fernandez, P. 1999. Nested polymerase chain reaction for detection of Theileria annulata and comparison with conventional diagnostic techniques: its use in epidemiological studies. Parasitology Research. 85: 243245.

Modi, D.V., Bhadesiya, C.M. and Mandali, G.C. 2015. Haemato-biochemical Changes in Cross-bred Cattle Infected with Theileria annulata in Banaskantha District of Gujarat. International Journal of Scientific and Research Publications. 5(1): 1-4.

Omer, O.H., El-Malik, K.H., Mahmoud, O.M., Haroun, E.M., Hawas, A., Sweeney, D. and Magzoub, M. 2002. Haematological profiles in pure bred cattle naturally infected with Theileria annulata in Saudi Arabia. Veterinary Parasitology. 107: 161-168.

Radostits, O.M., Gay, C.C., Hinchcliff, K.W. and Constable, P.D. 2007. Veterinary medicine: A textbook of the diseases of cattle, horses, sheep, pigs and goats, tenth ed. Elsevier, Philadelphia.

Saeid, R.N.F., Khalili, M. and Ghalekhani, N. 2013. Detection of Theileria annulata in blood samples of native cattle by PCR and smear method in Southeast of Iran. Journal of Parasitic Disease. DOI 10. 1007/s 12639-013-0333-2.

Sayin, F., Karaer, Z., Dincer, S., Cakmak, A., Inci, A., Yukari, B.A., Eren, H., Vatansever, Z., Nalbantoglu, S. and Melrose, T.R. 2003. A comparison of susceptibilities to infection of four species of Hyalomma ticks with Theileria annulata. Veterinary Parasitology. 113(2): 115-121.

Shahnawaz, S., Ali, M., Aslam, M.A., Fatima, R., Chaudhary, Z.I., Hassan, M.U., Ali, M. and Iqbal, F. 2011. A study on the prevalence of a tick transmitted pathogen, Theileria annulata, the haematological profile of cattle from Southern Punjab (Pakistan). Parasitology Research. 109: 1155-1160. 
Singh, A., Singh, J., Grewal, A.S. and Brar, R.S. 2001. Study on some blood parameters of cross-bred calves with experimental Theileria annulata infections. Veterinary research communications. 25: 289-300.

Singh, S.K., Sudan, V., Singh, A.P. and Yadav, B.K. 2014. Evaluation of Clinical Markers for Diagnosis of Bovine Theileriosis: A Study of 21 Calves. Intas Polivet. 15(1): 91-95.

Soulsby, E.J.L. 1982. Helmints, arthropods and protozoa of domesticated animals, seventh ed. Baillier, Tindall and Cassel Ltd., London.

Stockham, S., Kjemtrup, A., Conrad, P., Schmit, D., Scott, M., Robinson, T., Tyler, J., Jonson, G., Carson, C. and
Cuddihee, P. 2000. Theileriosis in a Missouri beef herd caused by Theileria buffeli: case report, herd investigation, ultrastructure, phylogenetic analysis, and experimental transmission. Veterinary Pathology. 37: 11-21.

Tanwar, R.K., Gahlot, A.K., Yadav, J.S., Sharma, S.N. and Lodha, K.R. 1984. Theileriosis (Theileria annulata) in indigenous Rathi calves. Indian Journal of Animal Science. 54: 118-120.

Tuli, A., Singla, L.D., Sharma, A., Bal, M.S., Filia, G. and Kaur, P. 2015. Molecular epidemiology, risk factors and haematochemical alterations induced by Theileria annulata in bovines of Punjab (India). Acta Parasitologica. 60(3): 378390.

\section{How to cite this article:}

Pavan Goyal, Anju Chahar, R.K. Tanwar, Fakhruddin and Shringi, B.N. 2018. HospitalPrevalence of Theileria annulata Infection in Cattle-Calves Determined by Blood Smear and Lymph Node Aspirate Smear Examination in Bikaner, Rajasthan. Int.J.Curr.Microbiol.App.Sci. 7(06): 877-884. doi: https://doi.org/10.20546/ijcmas.2018.706.103 